\title{
Spinal Coccidioidomycosis: MR Imaging Findings in 41 Patients
}

\author{
(D)R.N. Crete, (DW. Gallmann, (D).P. Karis, and (D). Ross
}

\begin{abstract}
BACKGROUND AND PURPOSE: Coccidioides immitis is a dimorphic fungus endemic to the Southwest United States and Mexico, and at our institution, it is a relatively common pathogen presenting with a broad spectrum of associated spine diseases. We describe the various spinal manifestations resulting from coccidioidal infection and provide MR imaging examples from 41 pathologically proved cases.
\end{abstract}

MATERIALS AND METHODS: Retrospective electronic medical record and PACS searches were performed. Patients found to have both MR imaging findings positive for infection and confirmative biopsy and/or CSF studies were included. Abnormal MR imaging findings were identified, categorized, and quantified. Patient demographics and associated intracranial involvement if present were also recorded.

RESULTS: Forty-one patients were included. Positive findings were categorized as leptomeningeal enhancement (26 patients, $63 \%$ ), arachnoiditis (22 patients, 54\%), osteomyelitis-discitis (14 patients, $34 \%$ ), cord edema (11 patients, $27 \%$ ), and true syrinx (3 patients, $7 \%$ ). Thirty patients had documented brain involvement (73\%), most commonly in the form of basilar meningitis. Four patients were positive for HIV (10\%). Fifteen patients had pulmonary manifestations at presentation (37\%).

CONCLUSIONS: C immitis results in various spinal manifestations, most commonly leptomeningeal enhancement and arachnoiditis/ adhesive disease followed by osteomyelitis, which may resemble tuberculous or pyogenic infection on MR imaging.

ABBREVIATION: $\mathrm{T1}+\mathrm{C}=\mathrm{T1}$-weighted images with contrast

Coccidioides immitis is a dimorphic fungus well-known to be endemic to the Southwest United States and Mexico. ${ }^{1,2}$ At our institution, we experience $C$ immitis as a relatively common pathogen, presenting with variable pulmonary, intracranial, and spinal diseases regardless of immune status. The spectrum of spine disease reported in the literature is extensive, with involvement of the leptomeninges, epidural/paraspinal space, vertebral bodies both with and without disc involvement, and, rarely, the spinal cord. Although previous case reports and articles have discussed the imaging appearance of spinal coccidioidomycosis, to our knowledge, there has not been a comprehensive review of both intrathecal and vertebral/paraspinal involvement of this magnitude. ${ }^{3-9}$

Received April 29, 2018; accepted after revision August 9.

From the Department of Neuroradiology (R.N.C., W.G., J.P.K.), Barrow Neurological Institute, Phoenix, Arizona; and Department of Radiology (J.R.), Mayo Clinic College of Medicine, Phoenix, Arizona.

Paper previously presented at: Annual Meeting of the Western Neuroradiological Society, October 25-28, 2017; Koloa, Hawaii.

Please address correspondence to Ryan N. Crete, MD, Barrow Neurological Institute, Department of Neuroradiology, Dignity Health/St. Joseph's Hospital and

Medical Center, 350 West Thomas Rd, Phoenix, AZ 85013; e-mail:

Danielle.Andazola@dignityhealth.org

http://dx.doi.org/10.3174/ajnr.A5818
We describe the spinal MR imaging findings from 41 patients with pathologically proved Coccidioides infection.

\section{MATERIALS AND METHODS}

This retrospective study was approved by the St. Joseph Hospital and Medical Center institutional review board and was conducted in accordance with Health Insurance Portability and Accountability Act guidelines.

A broad retrospective search was performed using the electronic medical record for patients with a history of coccidioidomycosis during a 6-year period. Key words used for the search included "Coccidioides," "coccidioidomycosis," "cocci," and "valley fever." Patients were screened with spinal MR imaging and individually overread to evaluate abnormal findings. Patients with an abnormal spine MRI were then cross-referenced for evidence of true coccidioidal infection. True infection was defined as culture positive for $C$ immitis obtained from a paraspinal mass, fluid collection, or vertebral body or positive CSF complement fixation titers. Only patients found to have both MR imaging findings positive for infection and laboratory evidence of true infection were included. Abnormal MR imaging findings were categorized as cord edema, syrinx, cord enhancement, leptomeningeal 
Table 1: Patient demographics

\begin{tabular}{lc}
\hline & No. (\%) \\
\hline Ethnicity & \\
White & $17(41)$ \\
African American & $12(29)$ \\
Latino & $7(17)$ \\
Native American & $3(7)$ \\
Asian & $2(5)$ \\
Sex & \\
Male & $34(83)$ \\
Female & $7(17)$ \\
Patient age (mean) (SD) (yr) & $42.0(14.7)$ \\
\hline
\end{tabular}

Table 2: Abnormal findings on spinal MR imaging

\begin{tabular}{lc}
\hline & No. of Patients (\%) \\
\hline Leptomeningeal enhancement & $26(63)$ \\
Arachnoid adhesive disease & $22(54)$ \\
Osteomyelitis/discitis & $14(34)$ \\
Cord edema & $11(27)$ \\
Syrinx & $3(7)$ \\
\hline
\end{tabular}

Table 3: Distribution of intrathecal disease

\begin{tabular}{lccc}
\hline & $\begin{array}{c}\text { Leptomeningeal } \\
\text { Enhancement }\end{array}$ & $\begin{array}{c}\text { Adhesive } \\
\text { Arachnoiditis }\end{array}$ & $\begin{array}{c}\text { Cord } \\
\text { Edema/Syrinx }\end{array}$ \\
\hline Cervical & 23 & 14 & 9 \\
Thoracic & 20 & 11 & 9 \\
Lumbar & 19 & 18 & NA \\
\hline
\end{tabular}

Note:-NA indicates not applicable.

enhancement, arachnoiditis, and osteomyelitis-discitis with or without epidural/paraspinal abscess/phlegmon. Cord edema and syrinx were differentiated from one another by the degree of hypointensity on T1, in which syrinx more closely followed the CSF signal. Patient demographics, immune status, and the presence of associated intracranial or pulmonary involvement were also recorded.

During the 6-year period, patients were scanned using either GE (GE Healthcare, Milwaukee, Wisconsin) or Phillips (Phillips Healthcare, Best, the Netherlands) magnets at 1.5 or 3T. All patients included received intravenous gadolinium. Patients did not require total spine imaging to be included in the study.

Patients with intrathecal disease were screened for brain MR imaging and intracranial involvement. In patients without brain MR imaging, the posterior fossa was reviewed on cervical spine MR imaging to assess basilar meningitis.

\section{RESULTS}

Forty-one patients with confirmed $C$ immitis were identified as having abnormalities on spinal MR imaging. Of the 41 patients, 34 were men (83\%) and 7 were women (17\%). Seventeen patients were white (41\%); 12, African American (29\%); 7, Latino (17\%); 3, Native American (7\%); and 2, Asian (5\%) (Table 1). The average patient age was $42.0 \pm 14.7$ years.

Abnormal findings on intrathecal, vertebral/spinal, and intracranial MR imaging are addressed below and are summarized in Tables 2-5.

The most common finding was leptomeningeal enhancement (26 of 41 patients, 63\%) (Fig 1), often associated with arachnoiditis/adhesive disease (22 of 41, 54\%) (Fig 2). Cord edema was observed in 11 patients (27\%) (Fig $3 A$ ), and true syrinx was ob-
Table 4: Osteomyelitis-discitis distribution and characteristics

\begin{tabular}{lc}
\hline & $\begin{array}{c}\text { No. of } \\
\text { Patients (\%) }\end{array}$ \\
\hline Segment & \\
Cervical & $5(36)$ \\
Thoracic & $11(79)$ \\
Lumbar & $9(64)$ \\
Characteristic & \\
Paraspinal involvement & $11(78)$ \\
Disc involvement & $7(50)$ \\
Skip levels & $7(50)$ \\
Destructive (osseous) & $7(50)$ \\
Epidural involvement & $6(43)$ \\
Well-circumscribed (osseous) & $5(36)$ \\
Well-circumscribed (paraspinal) & $4(29)$ \\
Disc sparing with involvement of adjacent levels & $2(14)$ \\
Gibbus deformity & $1(7)$ \\
\hline
\end{tabular}

Table 5: Disease involvement and overlap

\begin{tabular}{lc}
\hline \multicolumn{1}{c}{ Abnormality } & No. of Patients (\%) \\
\hline Intrathecal disease & $30(73)$ \\
Discitis-osteomyelitis & $14(34)$ \\
Overlap & $3(7)$ \\
\hline
\end{tabular}

served in 3 patients ( $7 \%$ ) (Fig 3B-D). Cord enhancement was not definitively observed.

The distribution of intrathecal findings is summarized in Table 3. Leptomeningeal enhancement was most often diffuse and affected the cervical cord, thoracic cord, and conus medullaris/ cauda equina fairly evenly $(23,20$, and 19 patients, respectively). Adhesive arachnoiditis was most common in the lumbar spine where nerve root clumping was the most common finding (18 patients). Cervical and thoracic cord adhesive disease was observed in 14 and 11 patients, respectively. Collectively, cord edema and syrinx were observed equally in the cervical and thoracic cord (9 patients each). In total, 30/41 (73\%) patients had intrathecal involvement.

Fourteen of 41 patients presented with vertebral osteomyelitis and/or discitis (34\%, Fig 4). Disease distribution and characteristics are summarized in Table 4. Paraspinal involvement (Figs 5 and 6) was most common, occurring in 11 patients. Disc involvement, osseous destruction (Fig 4A), and skip lesions involving noncontiguous vertebral bodies occurred in 7 patients each. Epidural involvement (Figs 5 and 6) was identified in 6 patients. Well-circumscribed osteomyelitis was observed in 5 patients; 2 instances involved the disc space. Four patients had a well-circumscribed pattern of paravertebral/epidural phlegmon as well (Fig $4 B$ ). Sparing of the disc space and involvement of adjacent vertebral levels in a pattern resembling tuberculosis was observed in 2 patients (Fig 4C). Gibbus deformity (focal kyphosis) was observed in 1 patient (Fig 6). The thoracic spine was most commonly involved (11 patients).

Intracranial disease was identified in each (30/30) patient with intrathecal disease. Twenty-seven of 30 patients had MR imaging of the brain performed, while 3 other patients had evidence of posterior fossa involvement by cervical MR imaging. Nineteen of $30(63 \%)$ had either exclusively basilar or basilar-predominant leptomeningeal enhancement, while 4 patients (13\%) had diffuse leptomeningeal enhancement. Less typical intracranial manifestations identified included the following: middle cranial fossa 

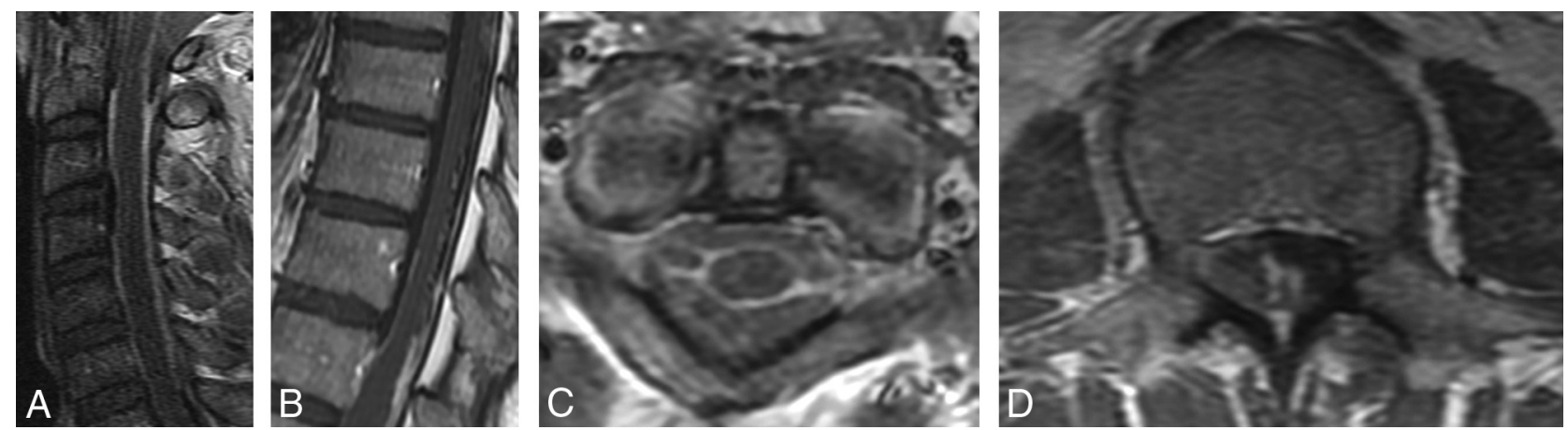

FIG 1. Leptomeningeal enhancement. Sagittal cervical $(A)$ and thoracic $(B)$ spine $T 1+C$ MR T1-weighted imaging with contrast show abnormal leptomeningeal enhancement, confluent in the cervical spine and patchy in the thoracic spine. Axial cervical (C) and lumbar (D) spine T1+C MR imaging show cord, cervical nerve root, and cauda equina nerve root leptomeningeal enhancement.
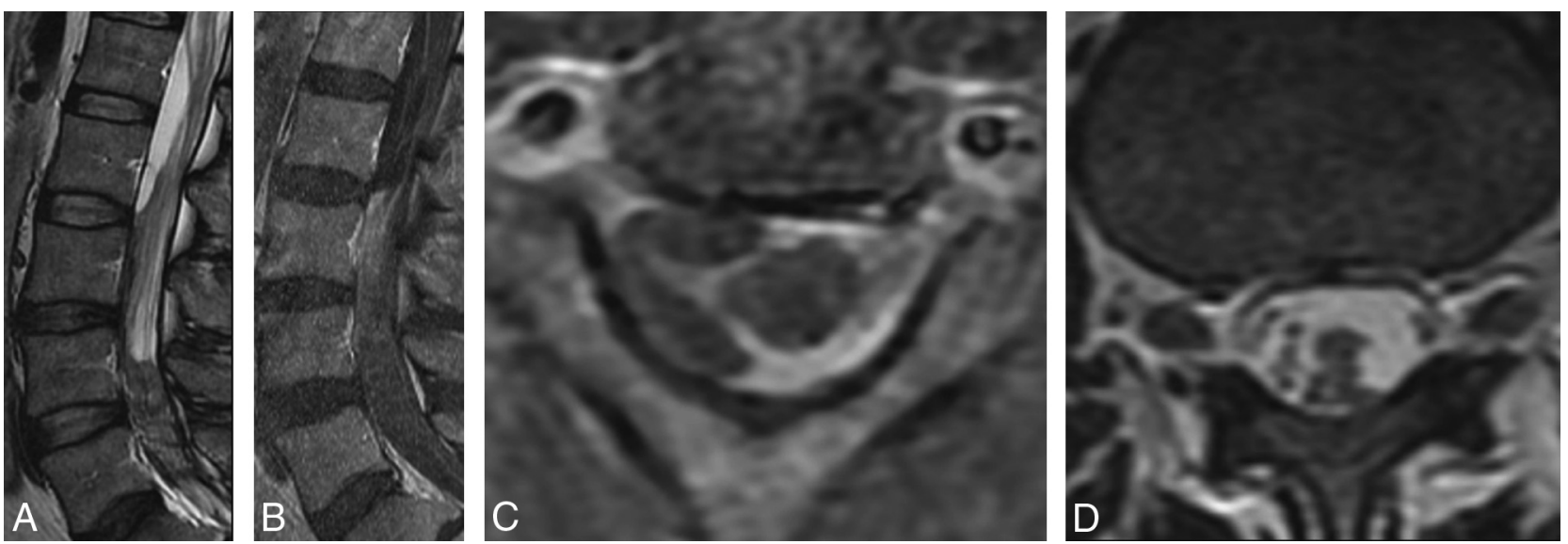

FIG 2. Arachnoiditis/adhesive disease. Sagittal T2 $(A)$ and $T 1+C(B)$ MR imaging of the lumbar spine show cauda equina nerve root clumping and enhancement. Note the dependent, nonenhancing purulent debris in the thecal sac on T2WI. Axial T1+C of the cervical spine $(C)$ shows tethering and deformity of the cord in addition to leptomeningeal enhancement. Axial T2 of the lumbar spine $(D)$ shows adhesive cauda equina nerve root clumping.
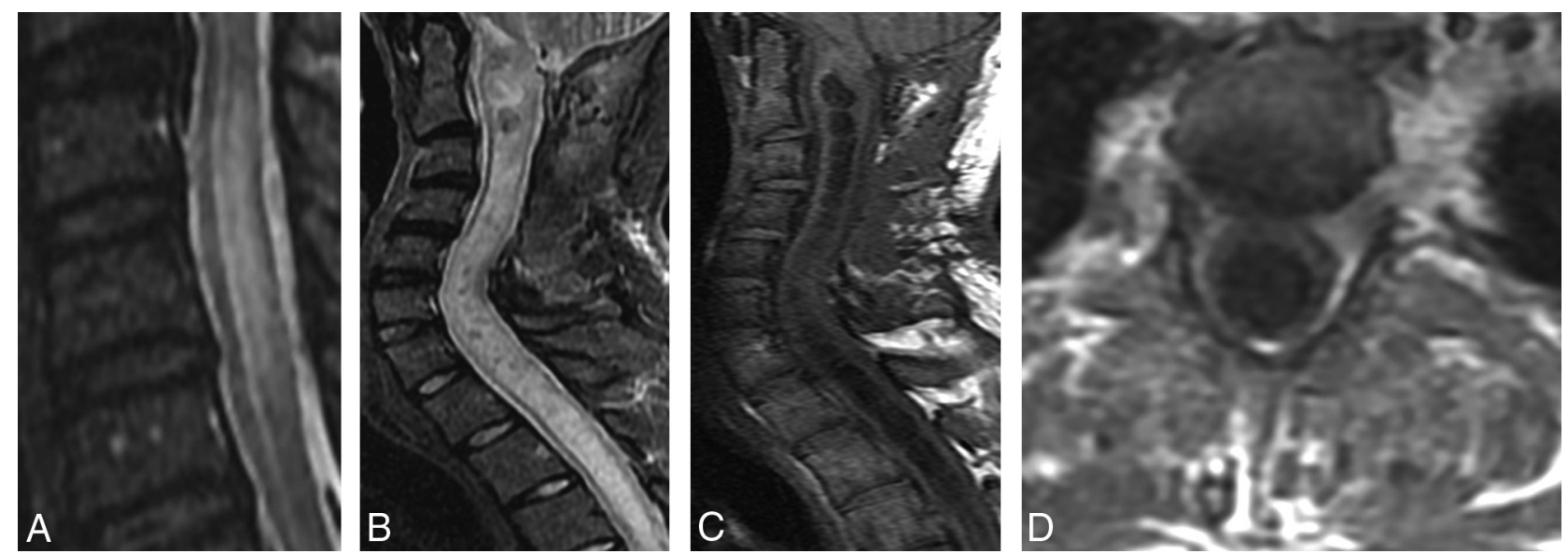

FIG 3. Cord edema and syrinx. Sagittal STIR images of the cervical spine show cord edema $(A)$ and true syrinx $(B)$. Sagittal T1 (C) shows true syrinx and exemplifies the utility of TIWI to differentiate true syrinx from edema states. Axial $T 1+C(D)$ shows no associated cord enhancement. Paraspinous enhancement in this image is related to postsurgical decompression.

pachymeningeal enhancement, diffuse pachymeningeal enhancement, prepontine abscess, suprasellar leptomeningeal enhancement, Sylvian fissure leptomeningeal enhancement, interpeduncular/infundibular enhancement, and right temporal lobe intra-axial and leptomeningeal enhancement.

Only three (7\%) patients in our study group had both intra- thecal and vertebral disease (Table 5). Each of these 3 patients had intracranial disease.

Four patients were positive for HIV (10\%). Fifteen patients had documented pulmonary involvement (36\%).

Patient clinical manifestations varied. Four patients (4/30) with intrathecal disease presented with acute myelopathy. Clinical 

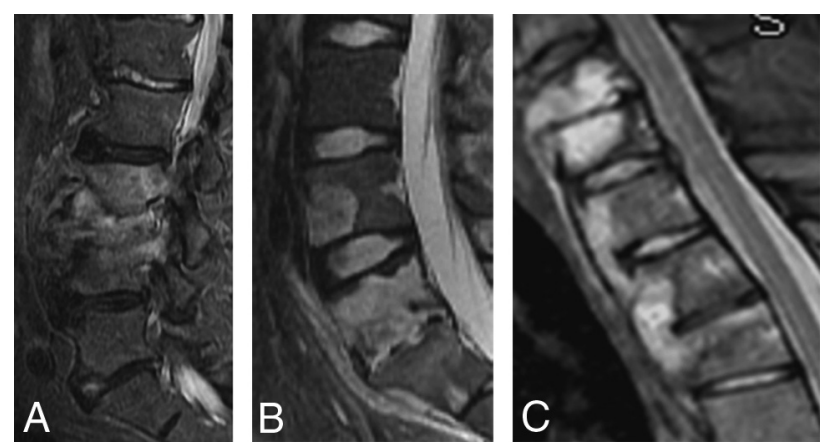

FIG 4. Osteomyelitis-discitis. Sagittal STIR of the lumbar spine $(A)$ shows destructive endplate changes similar to pyogenic disease at L3/4 with paravertebral phlegmon. Sagittal STIR of the lumbar spine (B) shows destructive endplate changes of $L 5 / S 1$, but note the wellcircumscribed nature of $L 5$ and the L4 skip lesion. Sagittal STIR of the cervicothoracic junction $(C)$ shows a well-circumscribed signal abnormality of the vertebral bodies with paravertebral phlegmon that appears to skip disc spaces, similar to tuberculous disease.
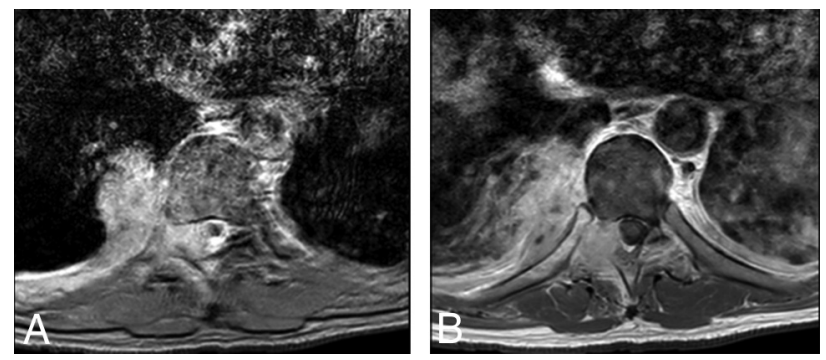

FIG 5. Axial T2 $(A)$ and $\mathrm{T} 1 \mathrm{C}+(B)$ sequences demonstrate right T8-9 paraspinal and epidural phlegmon, producing mild effacement of the thecal sac and leftward cord displacement.

history was considered incomplete for 5 patients with intrathecal disease (25 had sufficient information obtainable via the electronic medical record). The 4 are summarized as follows: quadriplegia secondary to severe cervical cord deformity/adhesive disease (Fig 7), quadriparesis secondary to a large loculated cervical cord syrinx (Fig 3C), neuropathic pain and quadriparesis secondary to cord edema and intermittent syrinx, and bilateral foot numbness secondary to extensive cord edema and arachnoid adhesive disease. Many other patients with ataxia had hydrocephalus along with other symptoms that could not be attributed solely to spinal disease.

\section{DISCUSSION}

Spinal infection with $C$ immitis is relatively common at our institution due to its location within a highly endemic region. Morbidity is high, and treatment strategies are complex and often lengthy. ${ }^{10,11}$ These observations illustrate the importance of understanding characteristic imaging findings to aid in diagnosis, especially in areas where a high index of suspicion must be maintained.

Osteomyelitis-discitis is a well-known association of infection with $C$ immitis. ${ }^{3,4,7,8}$ However, leptomeningeal disease is a more common manifestation. Extensive leptomeningeal enhancement involving the entire neural axis is common and requires complete spinal and brain imaging to evaluate the full extent. Only 5 patients with leptomeningeal enhancement did not have evidence of adhesive disease, but all patients with adhesive disease had lepto- meningeal enhancement, implicating both as related processes in which the antigen incites inflammation and inflammation plus exudate formation across time leads to adhesions.

The pathophysiology of the relationship to syrinx and cord edema is controversial. The Gardner hydrodynamic theory proposes that pulsatile ventricular CSF pressure is transmitted from the fourth ventricle to the central canal, eventually resulting in a progressive dilation (water-hammer effect) ${ }^{4}$ Only 1 case in our review demonstrated a dilated connection from the fourth ventricle to the central canal; however, it is most likely that syrinx and cord edema in the remainder of our patients are better explained by the theory that increased subarachnoid pressure due to CSF flow disturbances results in excess interstitial intramedullary fluid via the perivascular spaces. ${ }^{12}$ Increased intramedullary pulse pressures also promote circulatory disturbances within the cord and further intramedullary fluid accumulation. All patients with cord signal abnormality and syrinx had evidence of leptomeningeal disease.

Many patients with extensive leptomeningeal enhancement and cord edema were not myelopathic. This is congruent with the findings of Lammering et al, ${ }^{4}$ who noted that 7 of 8 patients with intrathecal disease were without back pain or radiculopathy. The 4 patients with myelopathy had syrinx formation or severe adhesion/cord deformity.

Meningitis is the most common and lethal form of disseminated coccidioidal disease, consisting of pyogranulomatous and fibroblastic processes affecting the meninges as well as the small vessels and perivascular zones. ${ }^{13}$ Once the intracranial meninges are involved, CSF dissemination can and often does occur. In our case review, 30/30 patients with intrathecal disease had evidence of intracranial involvement, most commonly in the form of basilar leptomeningitis (19/30). Lammering et $\mathrm{al}^{4}$ documented intracranial disease in 19/19 patients with intrathecal disease. It would appear that intrathecal involvement either does not or is highly unlikely to occur in the absence of intracranial involvement.

Osteomyelitis-discitis seen in the study population often resembled pyogenic spondylitis with aggressive endplate destruction and paravertebral phlegmon formation (7/14) (Fig 4A). ${ }^{6} \mathrm{~A}$ common misconception is that coccidioidal spondylitis is identical to tuberculous disease. Osteomyelitis that clearly spares the disc space commonly evokes the differential diagnosis of tuberculosis/fungal infection. This is not altogether incorrect; however, it leads to secondary misperception by affiliation. It suggests that because $C$ immitis is a fungus, it cannot appear similar to pyogenic disease. The origin of this error may stem from a survey report in the 1960s in which the authors observed only a single Trichophyton among 30 different fungal species that were capable of collagen digestion. The group included all major dimorphic mycotic pathogens, with the exception of C immitis. ${ }^{14,15}$ It was not until 1985 that a group in Nevada using different culture media observed that $C$ immitis could, in fact, digest collagen. ${ }^{16}$ The authors postulated that a fungal-specific collagenase or a more broadly functioning protease may be responsible. This finding appears to be unique to $C$ immitis among fungal species and explains the appearance often similar to pyogenic osteomyelitis-discitis.

Spinal infection with Coccidioides uncommonly resembled tuberculous spondylitis in our population, with sparing of the disc 

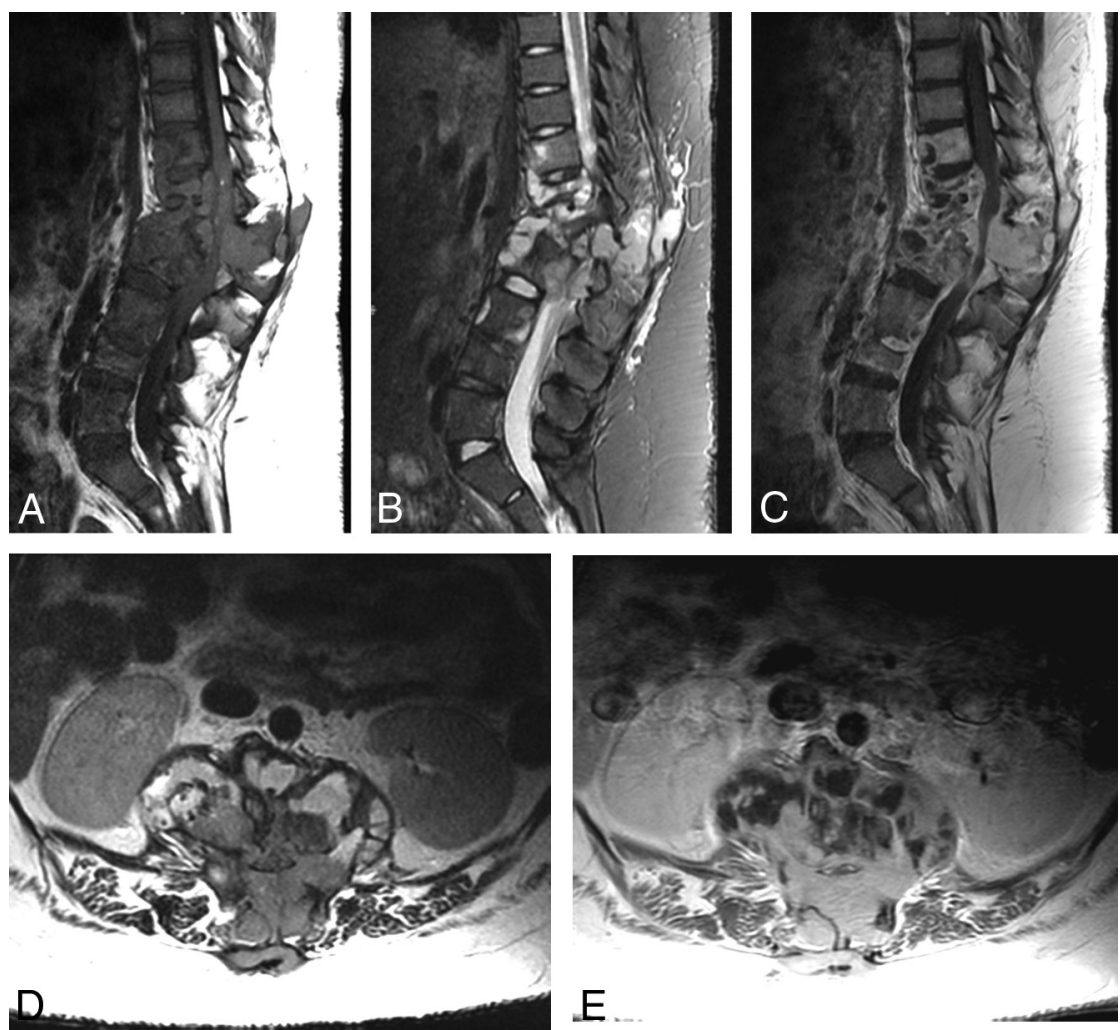

FIG 6. Sagittal $T \backslash(A), S T I R(B)$, and $T T C+(C)$ images depict destructive thoracolumbar spondylodiscitis with obliteration of the central canal, multilevel height loss, and associated kyphosis (Gibbus deformity).

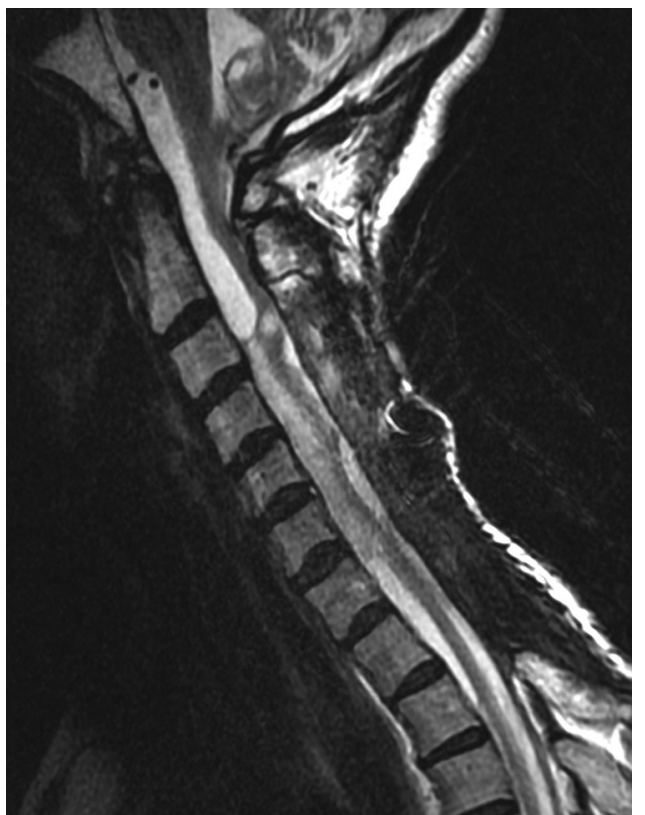

FIG 7. Sagittal T2-weighted image reveals severe multifocal cord tethering and deformity with associated intramedullary T2 signal at the $\mathrm{C} 3$ level.

spaces and involvement of adjacent vertebral levels (2/14) (Fig $4 C) .{ }^{17}$ Most interesting, a common finding was that of a wellcircumscribed osteomyelitis that does indeed involve the disc space (5/14) (Fig 4B), contrasting with typical aggressive pyogenic bone destruction. The authors of this study suggest the terminology of "clean" osteomyelitis-discitis when observing this pattern and considering coccidioidal disease, especially in endemic areas. Skip lesions are common, supporting the need for entire neuraxis imaging. Gibbus deformity, historically associated with tuberculous spondylitis, was observed in 1 patient.

Overlapping intrathecal/intracranial disease and spondylitis were observed in only 3 patients (7\%). The lack of overlap suggests alternate routes of infection (eg, CSF seeding versus hematogenous spread).

Intramedullary spinal cord enhancement was not a finding associated with coccidioidal infection in our study population. Such involvement has been reported rarely in the form of intramedullary abscess and enhancing intramedullary lesions. ${ }^{18,19}$

Men are much more commonly affected, potentially secondary to environmental/work exposure. The military has studied this extensively due to marine base locations in the San Joaquin Valley and frequent engagement in outdoor exercises. ${ }^{20,21}$ According to the 2016 US Census Bureau, $5 \%$ of the greater Phoenix, Arizona, population is composed of African Americans, and our study population was composed of $29 \%$ African Americans. ${ }^{22}$ This suggests a disproportionate amount of African Americans in the study group, implicating a predisposition, possibly due to genetics or secondary to occupational/environmental exposure. This finding is in concordance with other observations. ${ }^{2}$ Associated pulmonary disease is common and agrees with other investigations. ${ }^{4}$ Immunocompromised state is not required. In fact, only a minority of patients in our study were immunocompromised, suggesting complex host-pathogen interactions.

A recent neurosurgical review of spinal coccidioidomycosis included 140 patients and yielded similar patient characteristics. Males were disproportionately affected $(95 \%)$ as were African Americans (52\%). One-third of patients had concurrent pulmonary disease. ${ }^{23}$

\section{CONCLUSIONS}

The pathology associated with $C$ immitis infection is most commonly manifested as leptomeningeal enhancement and arachnoiditis, followed by osteomyelitis. Osteomyelitis and leptomeningeal disease are uncommonly seen simultaneously, suggesting different pathophysiology leading to infection. Cord edema and true syrinx states are secondary findings commonly seen in association with leptomeningeal disease. Coccidioidal spondylitis is protean and can mimic pyogenic spondylodiscitis, though it can also appear as well-circumscribed spondylitis with or without discitis. Skip lesions are common, necessitating imaging of the entire neuraxis. Myelopathy was an uncommon clinical presentation in 
our patient population, only documented in patients with syrinx or severe arachnoid adhesive disease.

\section{REFERENCES}

1. Pappagianis D. Epidemiology of coccidioidomycosis. In: Stevens DA, ed. Coccidioidomycosis: A Text (Current Topics in Infectious Disease). New York: Plenum Medical Book Company; 1980

2. Huntington RW, Waldmann WJ, Sargent JA, et al. Pathologic and clinical observations on 142 cases of fatal coccidioidomycosis. In: Ajello L, ed. Arizona State Department of Health. Coccidioidomycosis: Papers. Tucson: University of Arizona Press; 1967:221-25

3. Olson EM, Duberg AC, Herron LD, et al. Coccidioidal spondylitis: MR findings in 15 patients. AJR Am J Roentgenol 1998;171:785-89 CrossRef Medline

4. Lammering JC, Iv M, Gupta N, et al. Imaging spectrum of CNS coccidioidomycosis: prevalence and significance of concurrent brain and spinal disease. AJR Am J Roentgenol 2013;200:1334-46 CrossRef Medline

5. Zeppa MA, Laorr A, Greenspan A, et al. Skeletal coccidioidomycosis: imaging findings in 19 patients. Skeletal Radiol 1996;25:337-43 CrossRef Medline

6. Thrush A, Enzmann D. MR imaging of infectious spondylitis. AJNR Am J Neuroradiol 1990;11:1171-80 Medline

7. McGahan JP, Graves DS, Palmer PE. Coccidioidal spondylitis: usual and unusual radiographic manifestations. Radiology 1980;136:5-9 CrossRef Medline

8. Halpern AA, Rinsky LA, Fountain S, et al. Coccidioidomycosis of the spine: unusual roentgenographic presentation. Clin Orthop Relat Res 1979;78-79 Medline

9. Wesselius LJ, Brooks RJ, Gall EP. Vertebral coccidioidomycosis presenting as Pott's disease. JAMA 1977;238:1397-98 Medline

10. Kakarla UK, Kalani MY, Sharma GK, et al. Surgical management of coccidioidomycosis of the spine: clinical article. J Neurosurg Spine 2011;15:441-46 CrossRef Medline

11. Lewicky YM, Roberto RF, Curtin SL. The unique complications of coccidioidomycosis of the spine: a detailed time line of disease progression and suppression. Spine (Phila Pa 1976) 2004;29:E435-41 CrossRef Medline

12. Klekamp J. The pathophysiology of syringomyelia: historical overview and current concept. Acta Neurochir (Wien) 2002;144:649-64 CrossRef Medline

13. Mischel PS, Vinters HV. Coccidioidomycosis of the central nervous system: neuropathological and vasculopathic manifestations and clinical correlates. Clin Infect Dis 1995;20:400-05 CrossRef Medline

14. Rippon JW, Lorincz AL. Collagenase activity of Streptomyces (Nocardia) madurae. J Invest Dermatol 1964;43:483-86 CrossRef Medline

15. Rippon JW, Varadi DP. The elastases of pathogenic fungi and actinomycetes. J Invest Dermatol 1968;50:54-58 CrossRef Medline

16. Lupan DM, Nziramasanga P. Collagenolytic activity of Coccidioides immitis. Infect Immun 1986;51:360 - 61 Medline

17. Smith AS, Weinstein MA, Mizushima A, et al. MR imaging characteristics of tuberculous spondylitis vs vertebral osteomyelitis. AJNR Am J Neuroradiol 1989;10:619-25 Medline

18. Bajema KL, Dalesandro M Fredricks DN, et al. Disseminated coccidioidomycosis presenting with intramedullary spinal cord abscesses: management challenges. Med Mycol Case Rep 2016;15:1-4 CrossRef Medline

19. Tan LA, Kasliwal MK, Nag S et al. Rapidly progressive quadriparesis heralding disseminated coccidioidomycosis in an immunocompetent patient. J Clin Neurosci 2014;21:1049-51 CrossRef Medline

20. Standaert SM, Schaffner W, Galgiani JN, et al. Coccidioidomycosis among visitors to a Coccidioides immitis-endemic area: an outbreak in a military reserve unit. $J$ Infect Dis 1995;171:1672-75 CrossRef Medline

21. Brown J, Benedict K, Park BJ, et al. Coccidioidomycosis: epidemiology. Clin Epidemiol 2013;5:185-97 CrossRef Medline

22. 2017 U.S. Census Bureau QuickFacts: Arizona. https://www.census. gov/quickfacts/AZ. Accessed September 11, 2018

23. Martinez-Del-Campo E, Kalb S, Rangel-Castilla L, et al. Spinal coccidioidomycosis: a current review of diagnosis and management. World Neurosurg 2017;108:69-75 CrossRef Medline 